\title{
COMPARAÇÃO ENTRE A REAÇÃO DE FIXAÇÃO DE COMPLEMENTO E O TESTE DE POLARIZAÇÃO FLUORESCENTE NO DIAGNÓSTICO SOROLÓGICO DA BRUCELOSE EM BEZERRAS TABAPŨ̃ 30 DIAS APÓS A APLICAÇÃO DA VACINA B19
}

\author{
(COMPARISON BETWEEN COMPLEMENT FIXATION TEST AND FLUORESCENCE \\ POLARIZATION ASSAY IN THE SERODIAGNOSIS OF BRUCELLOSIS IN TABAPUÃ HEIFERS 30 \\ DAYS AFTER VACCINATION WITH B19 STRAIN)
}

\section{T. M. BLANKENHEIM ${ }^{1 *}$, F. A. R. CATALANO ${ }^{2}$, C. M. BERTONHA ${ }^{3}$, A. C. N. F. MAXIMO ${ }^{1}$, R. F. SANTOS ${ }^{4}$ L. A. MATHIAS ${ }^{5}$}

A vacinação com a amostra B19 de Brucella abortus é fundamental nos programas de controle dessa infecção. Contudo, a vacina induz títulos decrescentes de anticorpos, mas que podem provocar resultados falso-positivos. Muitas técnicas sorológicas já foram avaliadas para discriminar anticorpos vacinais, e há estudos mostrando que o teste de polarização fluorescente (TPF) apresenta elevada capacidade de discriminação mesmo em animais vacinados há pouco tempo. O estudo teve por objetivo comparar os resultados obtidos pelo TPF com aqueles obtidos pela reação de fixação de complemento (RFC) 30 dias após a aplicação da dose-padrão de vacina B19 em 71 bezerras da raça Tabapuã. Antes da vacinação, nenhuma das bezerras apresentava títulos de anticorpos. O TPF foi realizado e interpretado conforme as recomendações do fabricante (Diachemix, USA), e a para a RFC foi utilizada a microtécnica 50\% de hemólise recomendada por Alton et al. (1988). Os resultados obtidos nas técnicas foram comparados por meio de análise de regressão, após os títulos observados na RFC serem transformados em logaritmo de base 2. Os dados classificados em positivos e negativos foram comparados entre si usando o indicador kappa e o teste binomial. As análises de dados foram efetuadas por meio do software R. Apenas 6 animais apresentaram resultados negativos na RFC, e os títulos observados nesse teste chegaram a 1:128 (3 animais). O título mais frequente foi 1:16. $\mathrm{O}$ resultado mais elevado observado pelo TPF foi 127,3 mP. Observou-se uma associação positiva entre os resultados dos dois testes, com coeficiente de regressão 9,375 (IC 95\%: 6,762 - 11,988; P = 1,149 x $10^{-9}$ ) e $\mathrm{R}^{2}$ ajustado 0,4092 . Na RFC, $8,45 \%$ dos animais apresentaram resultado negativo, ao passo que no TPF a proporção de negativos foi o dobro (16,9\%). A diferença entre esses resultados foi estatisticamente significativa pelo teste binomial $(P=0,03125)$, e a concordância entre os resultados foi boa, com kappa 0,62 (IC 95\%: 0,41 - 0,84). Os dados obtidos indicam que o TPF apresentou melhor capacidade do que a RFC para discriminar anticorpos induzidos pela vacina B19, porém essa capacidade não foi tão elevada quanto a descrita por outros autores.

\footnotetext{
1 Doutoranda - Departamento de Medicina Veterinária Preventiva e Reprodução Animal, FCAV - UNESP, Jaboticabal, Via de Acesso Prof. Paulo Donato Castellani, s/nº, CEP: 14884-900, Jaboticabal, SP. *tmbvet@gmail.com 2 Mestrando - Departamento de Fisiopatologia Médica e Cirúrgica, FMVA - UNESP, Araçatuba

3 Mestranda - Departamento de Clínica e Cirurgia Veterinária, FCAV - UNESP, Jaboticabal

Mestranda - Departamento de Medicina Veterinária Preventiva e Reprodução Animal, FCAV - UNESP, Jaboticabal

5 Docente orientador - Departamento de Medicina Veterinária Preventiva e Reprodução Animal, FCAV - UNESP, Jaboticabal
} 